4. Feigin VL Anthology of stroke epidemiology in the 20th and 21st centuries: Assessing the past, the present, and envisioning the future. International Journal of Stroke. 2019. № 14 (3). P. 223-237.

DOI https://doi.org/10.30525/978-9934-26-038-4-10

\title{
VITAMIN D3 DEFICIENCY IN PATIENTS WITH PSORIATIC ARTHRITIS AND RELATIONSHIP WITH THE DISEASE MANIFESTATIONS
}

\author{
Grishyna O. I. \\ Ph. D. in Medicine,
}

Lead Research Associate at the Laboratory and Clinical Department of Molecular Immunopharmacology

State Institution «I. Mechnikov Institute of Microbiology and Immunology National Academy of Medical Sciences of Ukraine»

\author{
Menkus O. V. \\ Research Associate at the Laboratory and Clinical Department of Molecular \\ Immunopharmacology \\ State Institution «I. Mechnikov Institute of Microbiology and Immunology \\ National Academy of Medical Sciences of Ukraine» \\ Kharkiv, Ukraine
}

In rheumatology practice it is hard to find a disease where vitamin D deficiency has not been involved in the pathogenesis and the outcome in some extend. Murdaca G. et al. analyzed over 130 studies in order to find a correlation between vitamin D levels and its effect on several autoimmune diseases. The analysis demonstrated relationship between vitamin D and the development of several autoimmune diseases such as systemic lupus erythematous, thyrotoxicosis, type 1 diabetes, multiple sclerosis, iridocyclitis, Crohn's disease, ulcerative colitis, psoriasis vulgaris, seropositive rheumatoid arthritis, and polymyalgia rheumatica [1]. Recent comprehensive literature review Mohammed Saleh Al-Dhubaibi M.S. analyzed rigorously selected 20 studies included 2046 psoriatic patients with or without arthritis and 6508 healthy controls. From these 14 studies are in favor of a positive correlation between Vitamin D deficiency and psoriasis, while remaining six studies do not depict a positive correlation. It was claimed that more studies are required that would show an accurate and effective role of vitamin D deficiency in psoriasis [2]. 
Objective was to assess serum vitamin D3 level of in patients with psoriatic arthritis (PsA) and explore possible relationship with the disease manifestations.

Methods. Sixty eight patients with psoriatic arthritis were evaluated, 21 female and 47 male. All have chronic plaque psoriasis with plaque size not less than 2 centimeters in diameter. The presence of PsA was diagnosed according to the CASPAR (ClASsification criteria for Psoriatic ARthritis, 2006) criteria [3]. Skin type was classified by T.B. Fitzpatrick [4, P. 869-871]. Thirty healthy subjects served as a control group. The severity of psoriasis was assessed according to the PASI (Psoriasis Area and Severity Index) [5, P. 238-244. 6, P. 381-387], and the severity of psoriatic arthritis according to the PASDAS (Psoriatic Arthritis Disease Activity Score) [7, P. 1212-1217. 8, P. 749-756. 9, P. 986-991]. Serum 25(OH)D level in the peripheral blood was determined by enzyme-linked immunosorbent assay using kits «DRG 25-OH Vitamin D», manufactured by DRG International, Inc., USA. Serum concentration of 25(OH)D was assessed according to the Global Consensus Recommendations on Prevention and Management of Nutritional Rickets (2016): sufficiency > $50 \mathrm{nmol} / \mathrm{L}$, insufficiency -30-50 nmol / L, deficiency- < $30 \mathrm{nmol} / \mathrm{L}$ [10, P. 394-415].

Result. The average serum $25(\mathrm{OH}) \mathrm{D}$ level $(\mathrm{M} \pm \mathrm{SD})$ was significantly lower in patients with psoriatic arthritis comparing to control group $(34,1 \pm$ $9,7) \mathrm{nmol} / \mathrm{L}$ vs $(41 \pm 12,6) \mathrm{nmol} / \mathrm{L}, \mathrm{p}<0,05$. The patients were divided into 2 groups depending on D3 level. Group 1 consisted of 29 (42,6\%) patients, with vitamin D3 deficiency and 39 patients $(57,4 \%)$ with vitamin D3 level > $30 \mathrm{nmol} / \mathrm{L}$ formed group 2, respectively. The average serum 25(OH)D level in group 1 was $(28 \pm 7,6) \mathrm{nmol} / \mathrm{L}$ and in group $2(36 \pm 10,1) \mathrm{nmol} / \mathrm{L}$, $\mathrm{p}<0,05$. In group 1 there were 8 females $(27,6 \%)$ и 19 males and in the group 29 females $(20,5 \%)$ и 31 males, thus the groups were comparable by gender $\mathrm{p}>0,05$. However mean age $(\mathrm{M} \pm \mathrm{SD})$ in group 1 was higher $(51 \pm$ $11,2)$ vs $(46 \pm 8,4)$ years in group $2, p<0,05$. Duration of the disease from the first diagnosis was higher in group $1(18 \pm 5,1)$ years and comparing to group $2(11 \pm 3,2)$ years, $p<0,05$. At the beginning of the first symptoms the patient age did not significantly differ $(29 \pm 4,7)$ years in group 1 and $(28 \pm 4,2)$ in group $2, \mathrm{p}<0,05$. Among all patients skin type 2 and 3 by T.B. Fitzpatrick were found only, no difference between all groups. The severity of skin manifestations was higher in patients with vitamin D deficiency as confirmed by PASI, it was significantly higher in group $1(27,4 \pm 8,1)$ vs $(18,6 \pm 5,2)$ in group $2, p<0,05$. The severity of psoriatic arthritis was also higher in patients in group 1 , PASDAS was $(4,1 \pm 1,3)$ vs $(3,5 \pm 1,37)$ in group $2, \mathrm{p}<0,05$. Correlation analysis has shown negative correlation between serum 25(OH)D level and the disease duration $(r=-0,37)$, as well as PASI $(\mathrm{r}=-0,51)$ and PASDAS indexes $(\mathrm{r}=-0,42)$, respectively. 
Conclusions. In patients with psoriatic arthritis vitamin D3 deficiency was frequently found. There is a relationship between serum vitamin D3 level, duration of the disease and severity of both dermatologic and joint manifestations. Further studies exploring the complex role of vitamin D3 in psoriatic arthritis pathogenesis and severity are needed as well as appropriately designed clinical trials devoted to Vitamin D status correction and the disease manifestations. Disclosure statement. The authors report no conflicts of interest.

\section{References:}

1. Murdaca G., A., Tonacci A., Negrini S. et al. Emerging role of vitamin $\mathrm{D}$ in autoimmune diseases: An update on evidence and therapeutic implications. Epub 2019. URL: https://pubmed.ncbi.nlm.nih.gov/31323357/

2. Al-Dhubaibi M. Association between Vitamin D deficiency and psoriasis: An exploratory study. Int J Health Sci (Qassim). 2018 Jan-Feb. URL: https://www.ncbi.nlm.nih.gov/pmc/articles/PMC5870311/

3. Taylor W., Gladman D., Helliwell P. et al. Classification criteria for psoriatic arthritis: development of new criteria from a large international study. PMID: 16871531. 2006 Aug. URL: https://pubmed.ncbi.nlm.nih.gov/ $16871531 /$

4. Fitzpatrick T. The validity and practicality of sun-reactive skin types I through VI. Arch Dermatol. 1988. Vol. 124. P. 869-871.

5. Fredriksson T., Pettersson U. Severe psoriasis-oral therapy with a new retinoid. Dermatologica 197. 157(4). P. 238-244.

6. Jacobson C., Kimball A. Rethinking the Pso-riasis Area and Severity Index: the impact of area should be increased. Br J Dermatol 2004. № 151(2). P. 381-387.

7. Helliwell PS., FitzGerald O., Fransen J. Composite disease activity and responder indices for psoriatic arthritis: a report from the GRAPPA 2013 meeting on development of cutoffs for both disease activity states and response. J Rheumatol. 2014. Jun; 41(6). P. 1212-1217.

8. Helliwell PS., Kavanaugh A. Comparison of composite measures of disease activity in psoriatic arthritis using data from an interventional study with golimumab. Arthritis Care Res. 2014 May; 66(5). P. 749-756.

9. Helliwell PS., FitzGerald O., Fransen J. et al. The development of candidate composite disease activity and responder indices for psoriatic arthritis (GRACE project). Ann Rheum Dis. 2013 Jun;72(6). P. 986-991

10. Munns C. F., Shaw N., Kiely M. et al. Global Consensus Recommendations on Prevention and Management of Nutritional Rickets. J. Clin. Endocrinol. Metab. 2016. Vol. 101. № 2. P. 394-415. 